\title{
DESIGN OF A TRISO PARTICLE FUEL BASED INTEGRATED GAS- COOLED SPACE NUCLEAR REACTOR
}

\author{
Zeguang LI*, Jun SUN, Minggang LANG, Malin LIU, Xiaoyong YANG, Lei SHI \\ Institute of Nuclear and New Energy Technology, Collaborative Innovation Center of Advanced \\ Nuclear Energy Technology, Key Laboratory of Advanced Reactor Engineering and Safety of \\ Ministry of Education, Tsinghua University, Beijing, 100084, China \\ lizeguang@tsinghua.edu.cn, sunjun@tsinghua.edu.cn, langmg@tsinghua.edu.cn, \\ liumalin@tsinghua.edu.cn, xy-yang@tsinghua.edu.cn,shlinet@tsinghua.edu.cn
}

\begin{abstract}
According to versatile and long-lasting requirements of deep space missions, space nuclear reactor (SNR) power system is becoming a more suitable choice compared to traditional solar and chemical power systems in large-scale and long-life applications. From NASA's previous research, the gas-cooled reactor along with closed Brayton cycle (CBC) could achieve optimized weight-power ratio and be more applicable for large power system (100 $\mathrm{kWe}$ or MWe level). In this paper, a concept of integrated gas-cooled space nuclear reactor named IGCR-200 is introduced, which is designed based on the TRISO particle fuel and could achieve $200 \mathrm{kWe}$ output combined with highly efficient $\mathrm{He} / \mathrm{Xe} \mathrm{CBC}$ generator. The design requirements include an operation lifetime of at least 10 years in full power mode, maximum fuel temperature $<1600 \mathrm{~K}$, negative temperature reactivity feedback, passive decay heat removal, redundancy in reactor control, and sub-criticality during water flooding accidents. It has an outer diameter of $70.0 \mathrm{~cm}$, a height of $66.0 \mathrm{~cm}$ (reactor part), a total mass around $1000 \mathrm{~kg}$, total Uranium inventory of $226.8 \mathrm{~kg}$ (235U enrichment as 93\%), and $1 \mathrm{MW}$ thermal power output. The reactor physics, thermal hydraulics and other required analysis are taken out to show the feasibility and performances of the design.
\end{abstract}

KEYWORDS: space nuclear reactor, TRISO fuel particle, integrated fuel element, closed Brayton cycle

\section{INTRODUCTION}

The nuclear energy in space has been considered as a good option to provide steady and long-lasting electricity supply, especially in situations when and where the solar option is inadequate, impractical, or nonexistent [1]. With the increasing concern of outer planets exploration with large-scale electricity demands, as to Moon and Mars with manned missions, space nuclear reactors (SNRs) which could provide tens to hundreds of kilowatts electricity are getting more and more attentions according to the advantages in power level and power-weight ratio compared with RTGs [2]. Many studies of SNRs have been taken out, and from 1980s the researches are more focused on high power level space reactor systems which could provide hundreds of kilowatts or even megawatts electricity power [3-5].

The Institute of Nuclear and New Energy Technology (INET) at Tsinghua University has accumulated a lot of research experiences in TRISO particle fuel, inert gas process and direct Brayton cycle conversion system [6], which are the most important aspects in large-scale gas-cooled SNR design. With these 
research accumulations, different concepts of gas-cooled SNRs have been studied, which use specific designed TRISO particle fuel elements and are combined with Brayton conversion system.

In this article, a concept of integrated gas-cooled SNR named IGCR-200 is proposed, which is designed based on the TRISO particle fuel and could achieve $200 \mathrm{kWe}$ output power combined with highly efficient $\mathrm{He} / \mathrm{Xe} \mathrm{CBC}$ power conversion units (PCUs) [7]. The design requirements include an operation lifetime of at least 10 years in full power mode, maximum fuel temperature less than $1600 \mathrm{~K}$, negative temperature reactivity feedback, passive decay heat removal, redundancy in reactor control, and subcriticality during water flooding accidents. The reactor has an outer diameter of $70.0 \mathrm{~cm}$, a height of 66.0 $\mathrm{cm}$ (core part), a total mass around $1000 \mathrm{~kg}$, total Uranium inventory of $226.8 \mathrm{~kg}$ (235U enrichment as $93 \%$ ), and $1.0 \mathrm{MW}$ thermal power output.

\section{DESIGN OF THE REACTOR}

The IGCR-200 reactor is designed to provide 1.0 MW thermal power for 10 years of effective full power operation, and the average power density of the active core is about $13.5 \mathrm{MW} / \mathrm{m}^{3}$. The reactor has an integrated plate-fin heat exchange fuel element as the reactor core (as shown in Fig. 1), which is designed as a cylindrical metallic internal with a central channel and filled with optimized TRISO fuel particles and $\mathrm{BeO}$ axial reflectors. Inside the fuel element, 24 plate heat exchangers are placed uniformly in angle as the coolant channels, each of which has the width of $7.0 \mathrm{~mm}$ and the thickness of $1.5 \mathrm{~mm}$. As the reactor core has the outer shape of $\phi 45.0 \mathrm{~cm} \times \mathrm{H} 65.0 \mathrm{~cm}$, which is very small and leads to relatively large leakage to make the control drums in radial reflector have enough reactivity control worth.

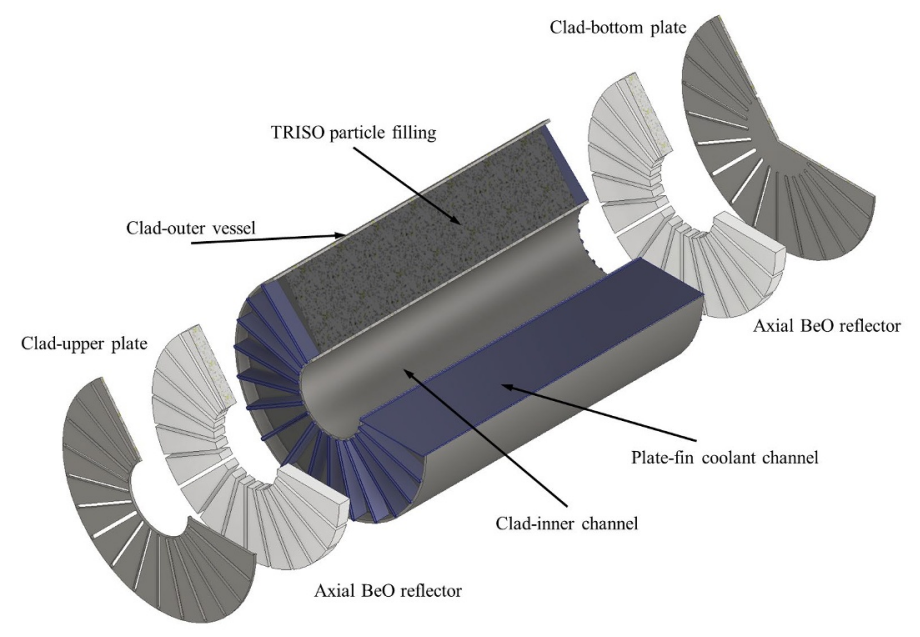

Figure 1. The design of integrated plate-fin fuel element.

The reactor pressure vessel (RPV) made by MA-ODS 956 steel [8] with $10.0 \mathrm{~mm}$ is placed between the integrated fuel element and radial reflector with the outer shape of $\phi 48.0 \mathrm{~cm} \times \mathrm{H} 72.5 \mathrm{~cm}$. This design could avoid the penetration of control drum drive mechanism into the RPV, which could cause difficult sealing problems in the space. The gaps between the reactor core and the pressure vessel consist the inlet coolant flow annulus in radial direction, and the top/bottom plenums in axial direction. As the axial reflectors are placed inside the integrated fuel element, outside the RPV only the BeO radial reflector is implemented which is designed to have an inner diameter of $48.4 \mathrm{~cm}$ and outer diameter (OD) of $70.0 \mathrm{~cm}$. 
To provide reactivity control over the operation life, $6 \mathrm{BeO} / \mathrm{B}_{4} \mathrm{C}$ control drums are incorporated inside the radial reflector each with $10.5 \mathrm{~cm}$ OD and cladded with $0.025 \mathrm{~cm}$ thickness MA-ODS 956. The control drums span the height of the radial reflector and each of them contains $1.0 \mathrm{~cm}$ thickness sector of $\mathrm{B}_{4} \mathrm{C}$ absorber with $120^{\circ}$ arc area inside the outer edge of the drum. Also, a special control system design named the control ring is proposed for the reactivity control in submerged accident conditions to avoid using safety rods or spectral shift absorbers [9]. The control ring is fixed inside the central channel of integrated fuel element, and $\mathrm{B}_{4} \mathrm{C}$ absorption material with certain concentration is doped into the control ring's composite. As the neutron spectrums in the control ring is moderated significantly when the central channel of integrated fuel element is filled with seawater or wet sand, the control ability of the control ring could get huge increase in the accident conditions than normal operation. With the implementation of control ring, it could have enough control ability in the submerged accidents along with the control drums without having significant influence in normal operation, also it could avoid sealing and welding difficulties in RPV design.

Fig. 2 shows the 3D view and coolant flow of the reactor. Some of the key design parameters are listed in Table I. Compared with previous reactor designs in JIMO project, the IGCR-200 reactor has advantages in overall size, total mass, the Uranium loading mass and so on.

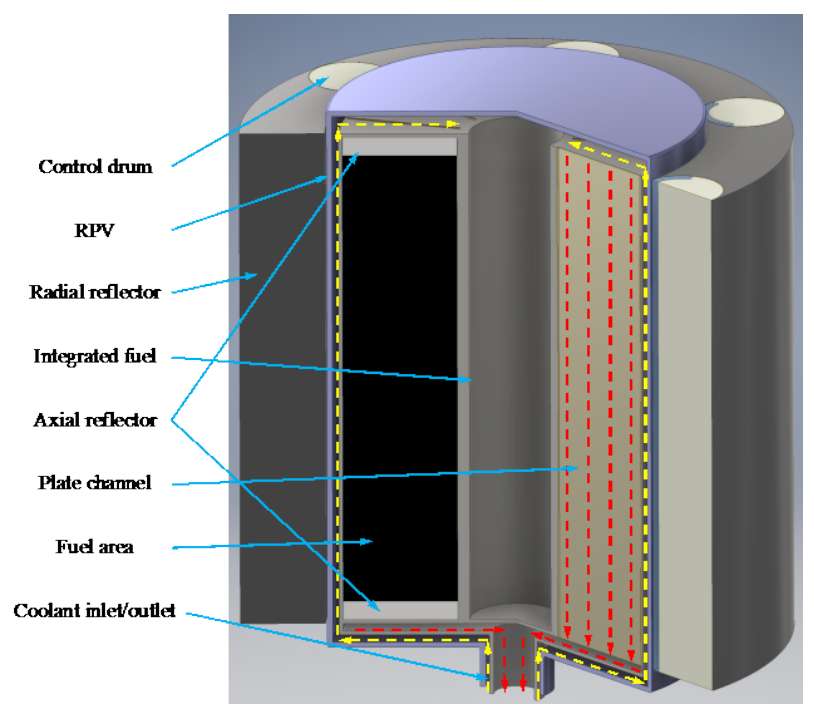

Figure 2. 3-dimension view and the coolant flow of the IGCR-200 reactor.

Table I. Key design parameters of IGCR-200 reactor.

\begin{tabular}{cccc}
\hline Parameter & Value & Parameter & Value \\
\hline Fuel element height $/ \mathrm{cm}$ & 65.0 & Fuel element OD / cm & 45.0 \\
Fuel area height $/ \mathrm{cm}$ & 60.0 & Fuel area volume $/ \mathrm{m}^{3}$ & 0.066 \\
TRISO particle diameter / mm & 0.5 & Particle volume fraction / \% & 55 \\
Fuel material & $\mathrm{UO}_{2}$ & U-5 enrichment / at $\%$ & 93 \\
Base filling material & $\mathrm{BeO}$ & Filling density / g/cm & 1.1 \\
RPV ID / cm & 46.0 & RPV OD / cm & 48.0 \\
Axial reflector thickness / cm & 2.5 & Radial reflector thickness / cm & 10.8 \\
Number of control drums & 6 & Control drum OD / cm & 10.6 \\
\hline
\end{tabular}




\begin{tabular}{cccc}
\hline Absorber material & ${ }^{10} \mathrm{~B}_{4} \mathrm{C}$ & Absorber thickness $/ \mathrm{cm}$ & 1.0 \\
Total thermal power / MW & 1.0 & Average power density / MW/m & 15.1 \\
Reactor height $/ \mathrm{cm}$ & 72.5 & Reactor OD $/ \mathrm{cm}$ & 70.0 \\
Uranium mass $/ \mathrm{kg}$ & 226.8 & Reactor total mass $/ \mathrm{kg}$ & 1037.2 \\
\hline
\end{tabular}

\section{NUMERICAL ANALYSIS RESULTS}

The numerical analyses have been taken out to give a better understanding of the characteristics of IGCR200 reactor, which include the neutronics analyses, thermal-hydraulics analyses and the comparison with previous designs in JIMO project. For the neutronics analyses, the reactivity results in different cases, control abilities of control drums and control ring and the burnup results are calculated. For the thermalhydraulics analyses, the temperature distribution and pressure drop of the fuel element in normal operation are calculated, and then the temperature changes with time are analyzed in Loss Of Coolant Accident (LOCA). Finally, the key parameters comparisons between IGCR-200 and other designs in JIMO project are taken out, including the mass, sizes, Uranium loading, output power and so on.

\subsection{Neutronics Analyses}

The neutronics analyses described in this section are performed using the Monte Carlo code RMC [10][11], and a set of continuous energy cross-section libraries from the ENDF-B VII.1 nuclear data was used in the analyses. The 3-D full core detailed model of IGCR-200 is established in the Monte Carlo calculations, and each of the results are performed with 10,000 neutrons per cycle and 1,500 total cycles with 500 inactive cycles.

First, the reactivity results are calculated in the following cases: (1) the cold clean excess reactivity $(300 \mathrm{~K}),(2)$ the cold clean shutdown reactivity, (3) the hot clean excess reactivity with operating temperature, (4) the cold clean reactivity of the reactor submerged in seawater, (5) the cold clean reactivity of the reactor submerged and flooded with seawater, and (6) the cold clean reactivity of the reactor submerged and flooded with seawater without radial reflector and control drums. In these cases, we consider that the worst-case submersion accident for IGCR-200 is consistently that with the reactor submerged in seawater but the voids inside RPV are not flooded with seawater (case (4)), in which the control ring can't achieve the highest control ability.

The reactivity results are listed in Table II. The effective delayed neutron fraction is chosen as 0.0072 according to the critical calculation with and without considering of delayed neutron. From the results we could notice, the IGCR-200 design has more than $\$ 4$ cold clean excess reactivity, which is normally required in SNR; and in the worst submersion accident case (3), the design still has more than $\$ 1$ subcritical which could satisfy the reactivity requirement in submersion accidents. Also, according to the Doppler effect of cross-section and thermal expansion of reactor, the IGCR-200 design has a negative temperature feedback to effective multiplication factor $k_{e f f}$ with the coefficient of $1.432 \times 10^{-5} \mathrm{~K}^{-1}$.

Table II. Reactivity results in different cases.

\begin{tabular}{ccccc}
\hline Case & Control drums & Core voids & $\boldsymbol{k}$ eff & $\boldsymbol{\rho} / \mathbf{\$}$ \\
\hline$(1)$ & All out & $\mathrm{He} / \mathrm{Xe}$ & $1.032026 \pm 0.000232$ & $4.448 \pm 0.032$ \\
$(2)$ & All in & $\mathrm{He} / \mathrm{Xe}$ & $0.958515 \pm 0.000225$ & $-5.762 \pm 0.031$ \\
$(3)$ & All out & $\mathrm{He} / \mathrm{Xe}$ & $1.023433 \pm 0.000232$ & $3.255 \pm 0.032$ \\
$(4)$ & All in & $\mathrm{He} / \mathrm{Xe}$ & $0.985926 \pm 0.000224$ & $-1.955 \pm 0.031$ \\
\hline
\end{tabular}




\begin{tabular}{lllll}
\hline$(5)$ & All in & Seawater & $0.913152 \pm 0.000221$ & $-12.062 \pm 0.031$ \\
$(6)$ & N/A & Seawater & $0.905467 \pm 0.000221$ & $-13.130 \pm 0.031$ \\
\hline
\end{tabular}

Furthermore, the control abilities of control drums and the effects of control ring are calculated. The control abilities of control drums are analyzed in the normal operation condition, and the effects of control ring are calculated at room temperature (300K). These results are presented in Fig. 3 and Table III.

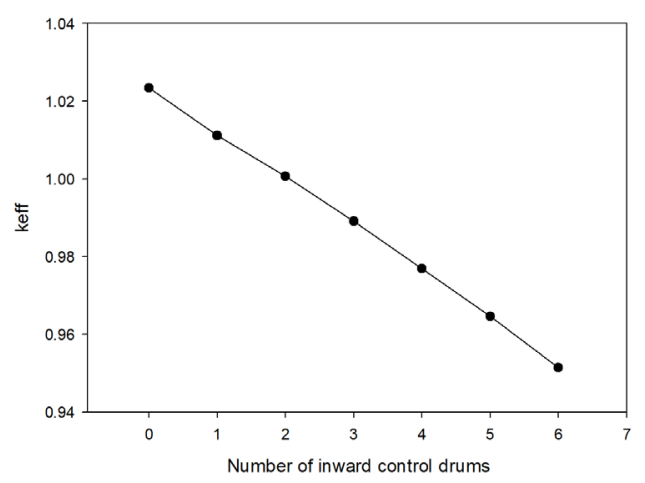

Figure 3. The change of $\boldsymbol{k}_{\text {eff }}$ with the number of inward control drums.

Table III. The effects of control ring in different cases.

\begin{tabular}{cccc}
\hline Case & $\boldsymbol{k}_{\text {eff }} \mathbf{W} / \mathbf{O}$ control ring & $\boldsymbol{k}_{\text {eff }}$ with control ring & Control ability / \$ \\
\hline$(1)$ & $1.052857 \pm 0.000233$ & $1.032026 \pm 0.000232$ & 2.893 \\
$(4)$ & $1.013128 \pm 0.000222$ & $0.985926 \pm 0.000224$ & 3.778 \\
$(5)$ & $0.983536 \pm 0.000225$ & $0.913152 \pm 0.000221$ & 9.776 \\
\hline
\end{tabular}

As the IGCR-200 is designed to have an operation life of at least 10 years in full power mode, the burnup calculations are performed to test the feasibility. In the burnup calculations, we set all the control drums are rotating to keep the absorption sector outward the core, and the reactor has the full power output of $1.0 \mathrm{MWth}$. Fig. 4 shows the results of $k_{\text {eff }}$ and maximum burnup with different operation days.

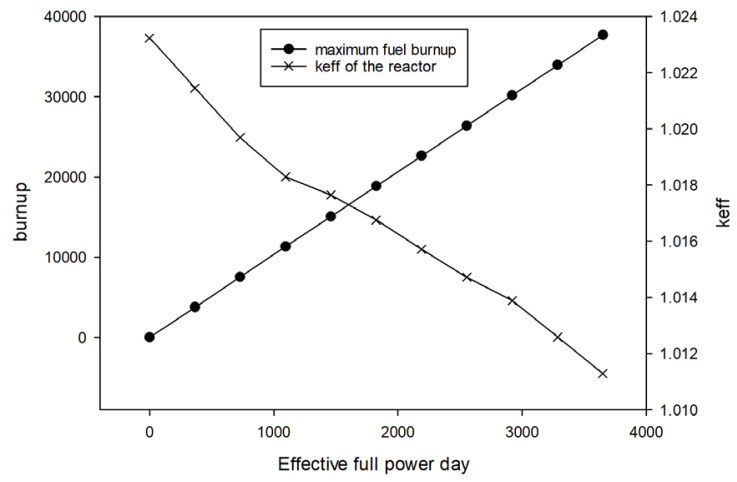

Figure 4. Burnup calculation results of IGCR-200. 


\subsection{Thermal-Hydraulics Analyses}

According to the complex geometry of IGCR-200 reactor, traditional system analysis codes are not suitable for the thermal-hydraulics analysis, therefore the CFD analysis code Fluent 14.0 is used instead. In the analyses, a typical structure of $1 / 48$ reactor including the fuel element, RPV and radial reflector (control drums are simplified as reflector) is chosen.

The thermal-hydraulics analyses of ICGR-200 in normal operation and LOCA accident condition have been taken out. Fig. 5 shows the static temperature results of IGCR-200 in the fuel element and top gap between fuel element and RPV. As the inlet and outlet are at the same side in IGCR-200 design, the maximum fuel temperature is around $1525 \mathrm{~K}$ and achieved on face A near inlet/outlet place. And Fig. 6 gives the results of temperature changes after LOCA accident.

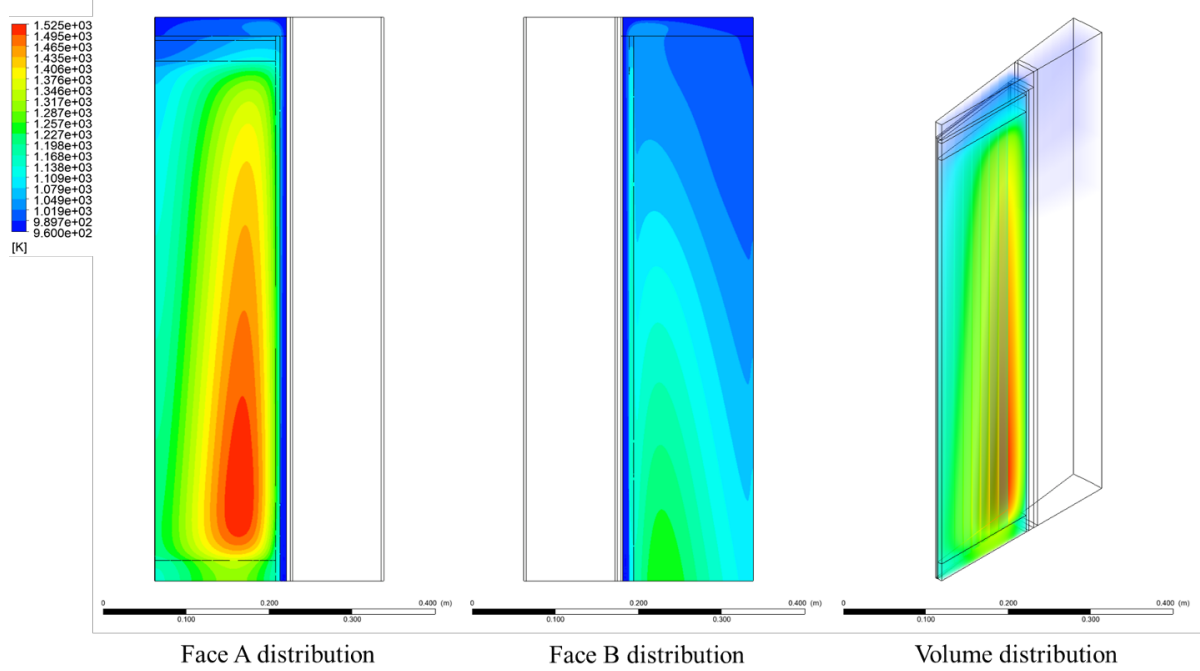

Figure 5. Temperature distributions of IGCR-200 reactor in normal operation

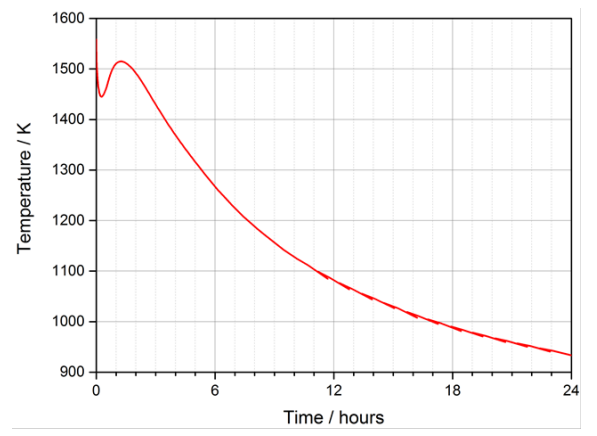

a) Maximum fuel temperature

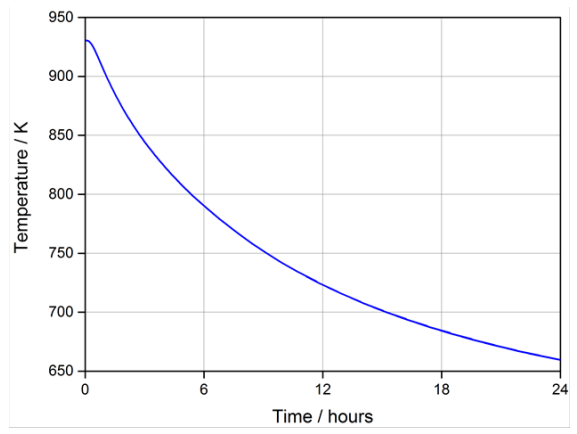

b) Radial reflector outer surface temperature

Figure 6. Temperate changes with time in LOCA accident 


\subsection{Comparison with Previous Designs}

Also, some key parameters of IGCR-200 have been compared with previous designs in JIMO project. Table IV gives the comparison results of IGCR-200 design and previous designs in JIMO project, from which we could find that the IGCR-200 design with TRISO particle based integrated plate-fin fuel element has significant advantages in geometry sizes, reactor mass, safety and so on.

Table IV. Comparison of key parameters of different designs..

\begin{tabular}{ccccc}
\hline Parameter & IGCR & JIMO base design & JIMO TZM & JIMO PCFD-474 \\
\hline Power / MWth & 1.0 & 1.0 & 1.0 & 1.0 \\
Fuel type & $\mathrm{UO}_{2}$ & $\mathrm{UO}_{2}$ & $\mathrm{UO}_{2}$ & UO $_{2}$ \\
Fuel form & TRISO based & Modular annular & Modular annular & Open lattice \\
& integrated plate-fin & flow block & flow block & 54.9 \\
Vessel OD / cm & 48.0 & 61.8 & 61.9 & 137.2 \\
Vessel height / cm & 72.5 & 159.6 & 149.8 & 78.5 \\
Reflector OD / cm & 70.0 & 85.1 & 85.4 & 283 \\
U235 loading / kg & 227 & 376 & 356 & 1340 \\
Reactor mass / kg & 1037 & 2078 & 1793 & 1775 \\
Peak fuel temp. / K & 1525 & 1773 & 1769 & \\
\hline
\end{tabular}

\section{CONCLUSIONS}

In this paper, a concept of integrated gas-cooled space nuclear reactor named IGCR-200 (Integrated GasCooled space Reactor) is introduced, which is designed based on the TRISO particle fuel and could achie ve $200 \mathrm{kWe}$ output with highly efficient $\mathrm{He} / \mathrm{Xe} \mathrm{CBC}$ generator. The design could satisfy the requirements including an operation lifetime of at least 10 years in full power mode, maximum fuel temperature $<1600$ $\mathrm{K}$, negative temperature reactivity feedback, passive decay heat removal, redundancy in reactor control, a nd sub-criticality during water flooding accidents. With a series of neutronics and thermal-hydraulics anal yses, this reactor has following advantages:

(1) Integrated plate-fin fuel element based on TRISO fuel particle technique.

(2) Special control ring design to avoid using safety rods or spectral shift absorbers.

(3) Inherent safety characteristics in neutronics and thermal-hydraulics.

(4) High coolant outlet temperature with a high CBC efficiency for the whole system.

In the future work, detailed structure and assembly designs of IGCR-200 reactor will be taken out, and related neutronics and thermal-hydraulics analyses based on detailed structure designs will be performed furthermore. Also, the startup process of IGCR-200 reactor, as an important feature in SNR design, will be studied in the further research.

\section{ACKNOWLEDGMENTS}

The research was funded by Chinese Major National S\&T under Grant number ZX069, Project 11775126 /11545013 by National Natural Science Foundation of China, Young Elite Scientists Sponsorship Program by CAST (2016QNRC001), and Tsinghua University Initiative Scientific Research Program. 


\section{REFERENCES}

1. M. S. El-Genk. "Deployment history and design considerations for space reactor power systems", Acta Astronautica, 64(9-10), pp. 833-849 (2009).

2. L. S. Mason. "A Comparison of Fission Power System Options for Lunar and Mars Surface Applications", Space Technology and Applications International Forum (STAIF-2006). 2006, American Institute of Physics (2006).

3. M. J. Wollman and M. J. Zika, Prometheus Project Reactor Module Final Report, For Naval Reactors Information, US (2006).

4. J. Ashcroft and C. Eshelman, "Summary of NR program Prometheus efforts", Proceedings of AIP Conference 2007, pp. 497-521 (2007).

5. J. C. King and M. S. El-Genk, "Submersion-Subcritical Safe Space (S4) reactor", Nuclear Engineering and Design, 236(17), pp. 1759-1777 (2006).

6. Z. Wu, D. Lin, et al., "The design features of the HTR-10", Nuclear Engineering and Design, 218(1), pp. 25-32 (2002).

7. J-M. P. Tournier and M. S. El-Genk, "Properties of noble gases and binary mixtures for closed Brayton Cycle applications". Energy Conversion and Management, 49, pp. 469-492 (2008).

8. M. S. El-Genk, J. Tournier, "A review of refractory metal alloys and mechanically alloyed-oxide dispersion strengthened steels for space nuclear power systems", Journal of Nuclear Materials, 340(1), pp. 93-112 (2005).

9. J. C. King, M. S. El-Genk, "Submersion criticality safety of fast spectrum space reactors: Potential spectral shift absorbers", Nuclear Engineering and Design, 236(3), pp. 238-254 (2006).

10. K. Wang, Z. Li, and et al., "RMC - A Monte Carlo code for reactor core analysis". Annals of Nuclear Energy, 82, pp. 121-129 (2015).

11. K. Wang, S. Liu, Z. Li, et. al, "Analysis of BEAVRS two-cycle benchmark using RMC based on full c ore detailed model", Progress of Nuclear Energy, 98, pp. 301-312 (2017). 